\title{
Perception of Menopausal Symptoms among Educated versus Non Educated Women by Using Menopausal Rating Scale (MRS)
}

\author{
Syeda Fakhar Batool, Yasmeen Saggu, Mansoor Ghani \\ Univrsity of Health Sciences Lahore, Lahore, Pakistan \\ Email: fakharbatool@gmail.com
}

Received 24 May 2014; revised 27 June 2014; accepted 17 July 2014

Copyright (C) 2014 by author and Scientific Research Publishing Inc. This work is licensed under the Creative Commons Attribution International License (CC BY). http://creativecommons.org/licenses/by/4.0/

\section{(c) (i) Open Access}

\begin{abstract}
Background: A cross sectional comparative study was conducted in a well populated city named Rawalpindi, which is located in the Northern part of Pakistan. Objectives: This study was aimed to document the comparison of menopausal-related symptoms among educated and non educated women of Rawalpindi, Pakistan. Methods: MRS was used to measure the intensity of menopausal symptoms. 100 educated and 100 uneducated women were selected for study purpose. Pakistan Institute of Medical Sciences, Military Hospital and Combined Military Hospital were selected as a study setting. Findings: Correlation \& Fisher exact test was applied for statistical analysis. The intensity of symptoms reported by Educated women as: sleeping problems (93.0\%); heart discomfort (80.0\%); hot flushes and sweating (70.0\%); joint and muscular pain (52.0); depressive mood (63.0\%); irritability (42\%); anxiety (60.0\%). physical and mental exhaustion; (48.0\%); sexual problem (61.0\%); dryness of vagina (57.0\%); and bladder problem (65.0\%). The severity of symptoms in uneducated women; sleeping problems (77.0\%); heart discomfort (73.0\%); hot flushes (69.0\%); joint and muscular pain (66.0); depressive mood (71.0\%); irritability (58\%); anxiety (80.0\%). physical and mental exhaustion (70.0\%); sexual problem (66.0\%); dryness of vagina (70.0\%); and bladder problem (83.0\%). Conclusions: Somatic symptoms were high in educated women as compare to uneducated women while the prevalence of psychological and Urogenital symptoms were high in uneducated women as compare to educated women.
\end{abstract}

\section{Keywords}

Perception, Menopause, Symptoms, Educated, Non Educated 


\section{Background}

The phase of womanhood starts from menarche [1]. Menarche is the beginning of a female's reproductive life or the first menstruation [2]. There are such intense physical, hormonal and psychological [3] changes in the body [4]. The word menopause is derived from month and pauses [5] and is a direct description [6] of the physiological event of woman's life where menstruation ceases to occur [7]. Estimated current figure of worldwide population is 6,892,900,000 and $52 \%$ is female population [8]. According to worldwide survey report 250 million women over 60 years passed through menopause each year where it is predicted that (1960) this population will increase by 1.2 billion by year 2030 and will increase 4.7 million a year [9].

Menopause may happen as natural menopause [10] or induced menopause. Natural menopause is absence of regular menstruation without any pathological cause due to reduction of estrogen and progesterone [11]. These changes occur due to the aging of ovaries which leads to decline in the production of ovarian gonadotrophins estrogen and progesterone [12]. The World Health Organization (WHO) defined menopause as the permanent absence of menstruation resulting from the cessation of the ovarian follicular activity [13]. Induced menopause is resulted due to the surgical removal of the female reproductive organ [14]. Changes in hormonal level cause various somatic, vasomotor, sexual and psychological symptoms that impair the overall quality of life [15]. The international data about the symptoms that are associated with menopause [16] [17], these are irritability (92\%), lethargy (88\%), depression (78\%), hot flashes and night sweats (75\%), headaches (71\%), forgetfulness (64\%), weight gain (61\%), insomnia (51\%), joint and muscle pain (48\%), palpitations (44\%), crying spells (42\%), constipation (37\%), dysuria (20\%), and decreased libido (20\%). Limited and insufficient data is available in Pakistan on menopause [9] [18]. Menopausal rating scale used for the assessment of menopausal symptoms, which is designed to assess menopause specific health related quantity of life (QoL) and internationally validated assessment tool [19] [20].

\section{Materials and Methods}

Descriptive, cross sectional survey was conducted at Rawalpindi and Islamabad Pakistan. Pakistan institute of Medical sciences (PIMS), Combined Military Hospital and Military Hospital was selected as the study setting. 200 women age 45 to 55 years attending Obstetrics and Gynaecology outpatient \& inpatient department were interviewed. Informed consent was taken. The predesigned questionnaire was used to collect the information regarding socio demographic data; Menopausal Rating Scale (MRS) was used.

All the data was analyzed by utilizing Statistical Package for Social Sciences (SPSS) 19.0 version.

Menopause Rating Scale (MRS) which is designed to assess menopause specific health related quantity of life (QoL) to measure the severity of symptoms. The MRS is composed of 11 items and was divided into three subscales: a) somatic-hot flushes, heart discomfort/palpitation, sleeping problems and muscle and joint problems; b) psychological-depressive mood, irritability, anxiety and physical and mental fatigue and c) urogenital-sexual problems, bladder problems and dryness of the vagina. Each of the eleven symptoms limited a scoring scale from 0 - 4 [19] [20]. Reliability coefficient was found to 0.84 and all items of MRS significantly correlated with total test scores.

\section{Results}

Two hundred menopausal women were approached for the selection of participants in the study of which 100 were educated and 100 were uneducated, Results were analyzed through SPSS 19 version and found that the age of women ranged from 45 to 55years and mean age was 50.1. In this study $\mathrm{n}=102(52.0 \%)$ were from the age group of 45 - 50 years. $n=98(48.0 \%)$ were from the age group of $50-55$ years.

Chi square test were used to compare categorical and continuous data, respectively. The items of the MRS are also presented as frequencies (present or not). A $p$ value of $<0.05$ was considered as statistically significant. Total score as well as per each subscale of the MRS significantly increased in relation to education. Women with lower educational level presented higher Urogenital and psychological scorings in comparison to educated women. Educated women were having higher scoring of somatic symptoms than uneducated women. There were no other correlations in terms of scores and other socio-demographic data.

Table 1 shows the marital status of respondents the total number of respondents were 200 out of which $n=$ 196 (98.0\%) were married and $n=4(2.0 \%)$ were widow as reported by the study participants in their demo- 
graphic data.

Table 2 represents the Sciodemographic data like educational milieu, employment status and education status of the participants of this study, that among the total 200 participants. $n=52(26.0 \%)$ were illiterate, $n=43$ (21.5.0\%) had got their religious education from madrassa, $n=5(2.5 \%)$ had primary education $n=21(11.0 \%)$ were Matriculates, $n=46$ (23.0\%) had done their intermediate, $n=25$ (12.5\%) had graduate degree, and $n=8$ (4.0\%) had postgraduate degree. This table also reveals the nature of job of the respondents their work is comprised as self employed and employed $n=26(12.5 \%)$ were house wives. $n=74(37.0 \%)$ mentioned in the table that majority of the participants were employed on private or Govt-job. This table also depicts the family monthly income. The study finding shows total participants $n=200$ the estimated monthly household income was 5000 to 10,000 rupees for $n=63$ (31.5\%) where as $n=86$ (43.5\%) participants had an income of more than 10,000 rupees per month therefore but $n=11$ (5.5\%) do not know about their monthly income. this study reported the median family income as mean could pulled towards the extreme value more than 10,000.

According to the results, the correlation between somatic and education is $0.158^{*}$ which shows a significant association. It means that the education has an impact on somatic symptoms according to the significant at the 0.05 level. Psychological and education shows a strong significance on each other i.e. $0.679^{* *}$. It means that they have shows an impact on each other at 0.01 level. Psychological and somatic symptoms have also a strong association i.e. $0.316^{* *}$. And the significant level of Urogenital is $0.347^{* *}$ according to the significant at the

Table 1. Marital status of participants.

\begin{tabular}{ccc} 
& Frequencies & Percentages \\
Married & 193 & $95.5 \%$ \\
Widows & 7 & $3.5 \%$ \\
Total & 200 & 200 \\
\hline
\end{tabular}

Table 2. Scio-demographic varriables.

\begin{tabular}{|c|c|c|}
\hline \multirow{10}{*}{ Education status } & Demographic data & Percentages \\
\hline & Married & $95.5 \%$ \\
\hline & Widows & $3.5 \%$ \\
\hline & Illiterate & $26.0 \%$ \\
\hline & Madrassa & $21.5 \%$ \\
\hline & Primary & $2.5 \%$ \\
\hline & Metric & $11.0 \%$ \\
\hline & F.A/FSc & $23.0 \%$ \\
\hline & B.A/BSc & $12.5 \%$ \\
\hline & M.A/MSc & $4.0 \%$ \\
\hline \multirow{3}{*}{ Employment status } & House wives & $30.0 \%$ \\
\hline & Self employed & $19.5 \%$ \\
\hline & Govt\& private Jobs & $50.5 \%$ \\
\hline \multirow{4}{*}{ Monthly income } & $<5000$ & $20.0 \%$ \\
\hline & $5-1000$ & $31.5 \%$ \\
\hline & More than 10,000 & $43.0 \%$ \\
\hline & Don't know & $5.5 \%$ \\
\hline
\end{tabular}

$\mathrm{N}=200$. 
Statistical analysis of educated and non educated women

\begin{tabular}{cccc}
\hline Items & Symptoms & Educated & Non educated \\
\hline 1 & •Somatic & $\mathbf{7 6 \%}$ & $\mathbf{6 9 \%}$ \\
2 & Hot flushes & $78 \%$ & $69 \%$ \\
3 & Heart discomfort & $80 \%$ & $73 \%$ \\
11 & Sleeping problems & $93 \%$ & $77 \%$ \\
& Joint and muscular pain & $52 \%$ & $66 \%$ \\
4 & $\bullet$ Psychological & $\mathbf{5 3 \%}$ & $\mathbf{7 0 \%}$ \\
5 & Depressive mood & $63 \%$ & $71 \%$ \\
6 & Irritability & $42 \%$ & $58 \%$ \\
7 & Anxiety & $60 \%$ & $80 \%$ \\
& Physical \& mental exhaustion & $48 \%$ & $70 \%$ \\
8 & •Urogenital & $\mathbf{6 1 \%}$ & $\mathbf{7 3 \%}$ \\
9 & Sexual problems & $61 \%$ & $66 \%$ \\
\hline 10 & Bladder problems & $65 \%$ & $83 \%$ \\
\hline & Dry vagina & $57 \%$ & $70 \%$ \\
\hline
\end{tabular}

The Overall difference among educated and non educated women

\begin{tabular}{ccccc}
\hline & \multicolumn{3}{c}{ Correlation } \\
\hline & Education & Somatic & Psychological & Urogenital \\
\hline Education & 1 & & \\
Somatic & $0.158^{*}$ & 1 & \\
Psychological & $0.679^{* *}$ & $0.316^{* *}$ & 1 & \\
Urogenital & $0.347^{* *}$ & $0.258^{* *}$ & $0.410^{* *}$ & 1 \\
\hline
\end{tabular}

$\mathrm{N}=200,{ }^{*}$ Correlation is significant at the 0.05 level (1-tailed), ${ }^{* *}$ Correlation is significant at the 0.01 level (2-tailed).

0.01 level. It shows a positive strong significant on education. On the other hand the correlation between Urogenital and somatic symptoms are $0.258^{* * *}$ which is highly significant which shows that the Urogenital has a strong significant impact on somatic, and also Urogenital and psychological symptoms are also shows a strong significant association i.e. $0.410^{* *}$ at 0.01 level.

\section{Discussion}

Menopause is a serious public health problem in developing countries and is associated with age, education, sexuality, depression and sexual problems. Recent studies also provide strong evidence that menopausal symptoms are associated with somatic, psychological and sexual problems [11]. In present study significant difference was noted among educated and uneducated women as the prevalence of menopausal symptoms is higher in uneducated women due to lack of awareness and their cultural variations.

In present study the most prevalent symptoms reported by Educated women include, sleeping problems (93.0\%); heart discomfort (80.0\%); hot flushes and sweating (70.0\%); joint and muscular pain (52.0); depressive mood (63.0\%); irritability (42\%); anxiety (60.0\%). physical and mental exhaustion; (48.0\%); sexual problem (61.0\%); dryness of vagina (57.0\%); and bladder problem (65.0\%). The most prevalent symptoms reported by uneducated women, sleeping problems (77.0\%); heart discomfort (73.0\%); hot flushes and sweating (69.0\%); joint and muscular pain (66.0); depressive mood (71.0\%); irritability (58\%); anxiety (80.0\%); physical and 
mental exhaustion (70.0\%); sexual problem (66.0\%. (70.0\%); and bladder problem (83.0\%).

Symptoms reported from different regions of Pakistan were also different. In our study frequency of menopausal symptoms varied from $21.08 \%$ to $75.66 \%$ commonest symptom reported were Backache, Body ache and Insomnia 653 (75.66\%), 576 (66.74\%) and 544 (63.4\%) respectively. Similar symptoms were reported in another study from Hyderabad Sindh [21]. Whereas commonest symptom reported from Punjab were lethargy 65.4\%, urinary symptom 56.2\% and agitation 50.8\%. 22 Commonest symptom reported in astudy from Karachi Sindh were Body ache $86 \%$, Hot flushes $86 \%$ and irritability $65 \%$ [11].

Another study conducted by Zöllner YF In Germany (2005) on menopausal symptoms; the most prevalent symptoms reported were joint and muscular discomfort (80.1\%); physical and mental exhaustion (67.1\%); and sleeping problems (52.2\%). Followed by symptoms of hot flushes and sweating (41.6\%); irritability (37.9\%); dryness of vagina (37.9\%); anxiety (36.5\%); depressive mood (32.6\%). Other complaints noted were sexual problem (30.9\%); bladder problem (13.8\%) and heart discomfort (18.3\%). this difference is existed due to cultural \& environmental variations among these two countries.

A cross-sectional study Conducted in 2007on Malaysian women the reported symptoms were: joint and muscular discomfort (80.1\%), physical and mental exhaustion (67.1\%) and sleeping problems (52.2\%). This was followed by symptoms of hot flushes and sweating (41.6\%), irritability (37.9\%), dryness of vagina (37.9\%), anxiety (36.5\%), depressive mood (32.6\%), sexual problem (30.9\%), bladder problems (13.8\%) and heart discomfort/palpitation (18.3\%). This study is also congruent to present study.

\section{Conclusion}

The prevalence of menopausal symptoms found in this study that intensity of somatic symptoms were high in educated women as compare to uneducated women while the prevalence of psychological and Urogenital symptoms were high in uneducated women as compare to educated women.

\section{Acknowledgements}

The authors would like to acknowledge the partial support of the University of Health Sciences Research Committee for this study; and would like to thank Ms. Yasmeen Saggu my supervisor \& Ms. Mansoor Ghani Coordinator University of Health Sciences. I also great thankful to Ms. Waqaslatif and Miss Anum Afandi for continue support regarding statistical analysis.

\section{Limitation of the Study}

There were number of limitations in this study:

-The use of convenience sampling limits to Rawalpindi and the results can not be generalized to other parts of the country.

-Limited sample size was not enough to validate the finding.

-Limited time of the study is a big limitation.

-Budgetary constraint.

\section{Implications of the Study}

This study has some important implications in nursing practice and nursing education. The findings of this study provide information that may help and guide nurses and other health care professionals about the individualized need and psychological support of menopausal women.

\section{References}

[1] Forouhari, S., Khajehei, M., Moattari, M., Mohit, M., Rad, S.M. and Ghaem, H. (2010) The Effect of Education and Awareness on the Quality of life in Postmenopausal Women. Indian Journal of Community Medicine, 35, 109-114. http://dx.doi.org/10.4103/0970-0218.62563

[2] Mishra, D.G., Cooper, R. and Kuh, D. (2010) A Life Course Approach to Reproductive Health: Theory and Methods MRC Unit for Lifelong Health and Ageing. Maturitas, 65, 92-97. http://dx.doi.org/10.4103/0970-0218.62563

[3] Burnett, S., Thompson, S., Bird, G. and Blakemore, J.S. Pubertal Development of the Understanding of Social Emotions: Implications for Education. Learning and Individual Differences, 21, 681-689. 
[4] Uskul, A.K. (2004) Women’s Menarche Stories from a Multicultural Sample. Social Science \& Medicine, 59, 667-679. http://dx.doi.org/10.1016/j.socscimed.2003.11.031

[5] Campbell, A. (2008) Attachment, Aggression and Affiliation: The Role of Oxytocin in Female Social Behavior. Biological Psychology, 77, 1-10. http://dx.doi.org/10.1016/j.biopsycho.2007.09.001

[6] Peter, C., Aguirre, W., Hidalgo, L. and Fayad, L. (2007) Assessing Menopausal Symptoms among Healthy Middle Aged Women with the Menopause Rating Scale. Maturitas, 57, 271-328. http://dx.doi.org/10.1016/j.maturitas.2007.01.009

[7] Kakkar, V., Kaur, D., Chopra, K., Kaur, A. and Kau, I.P. (2007) Assessment of the Variation in Menopausal Symptoms with Age, Education and Working/Non-Working Status in North-Indian Sub Population Using Menopause Rating Scale (MRS). Maturitas, 57, 306-314. http://dx.doi.org/10.1016/j.maturitas.2007.02.026

[8] U S Census Bureau—World POPClock Projection http://www.census.gov/ipc/www/popclockworld.html

[9] Yahya, S. and Rehan, N. (2002) Age, Pattern and Symptoms of Menopause among Rural Women of Lahore. Journal of Ayub Medical College Abbottabad, 9-12.

[10] Greendale, G.A., Lee, N.P. and Arriola, E.R. (1999) The Menopause Lancet. 1999; 353: 571-580.

[11] Hill, K. (1996) The Demography of Menopause. Maturitas, 23, 113-127. http://dx.doi.org/10.1016/0378-5122(95)00968-X

[12] World Health Organization Scientific Group: World Health Organization Research on the Menopause in the 1990s: Report of a. Technical Report Series. World Health Organization. 1996, (866): 14-16.

[13] Wulf, H. (1997) Utian’ Menopause-A Modern Perspective from a Controversial History. Maturitas, 29, 73-82.

[14] Moe, K.E. (2004) Hot Flashes and Sleep in Women. Sleep Medicine Reviews, 8, 487-497. http://dx.doi.org/10.1016/j.smrv.2004.07.005

[15] Ho, S.C., Chan, S.G., Yip, Y.B., Cheng, A., Yi, Q. and Chan, C. (1999) Menopausal Symptoms and Symptom Clustering in Chinese Women. Maturitas, 33, 219-227.

[16] Monterrosa, A., Blumel, J.E. and Chedraui, P. (2008) Increased Menopausal Symptoms among Afro-Colombian Women as Assessed with the Menopause Rating Scale. Maturitas, 59, 182-190. http://dx.doi.org/10.1016/j.maturitas.2007.12.002

[17] Karacan, S. (2010) Effects of Long-Term Aerobic Exercise on Physical Fitness and Postmenopausal Symptoms with Menopausal Rating Scale. Science \& Sports, 25, 39-46. http://dx.doi.org/10.1016/j.scispo.2009.07.004

[18] Green, J.G. (1998) Construction a Standard Climacteric Scale. Maturitas, 29, 19-24. http://dx.doi.org/10.1016/S0378-5122(98)00024-3

[19] Heinemann, L.A.J., Potthoff, P. and Schneider, H.P. (2003) International Version of the Menopause Rating Scale (MRS). Health and Quality of Life Outcomes, 1, 28. http://dx.doi.org/10.1186/1477-7525-1-28

[20] Qazi, A.R. (2006) Age, Pattern of Menopause, Climacteric Symptoms and Associated Problem among Urban Population of Hyderabad Pakistan. JCPSP, 16, 700-703.

[21] Jamelle, R.N. (1996) Awareness of Menopause and Pattern of Menopausal Symptoms in HRT Clinic. Pakistan Journal Of Obstetrics \& Gynecology, 9, 16-18. 
Scientific Research Publishing (SCIRP) is one of the largest Open Access journal publishers. It is currently publishing more than 200 open access, online, peer-reviewed journals covering a wide range of academic disciplines. SCIRP serves the worldwide academic communities and contributes to the progress and application of science with its publication.

Other selected journals from SCIRP are listed as below. Submit your manuscript to us via either submit@scirp.org or Online Submission Portal.
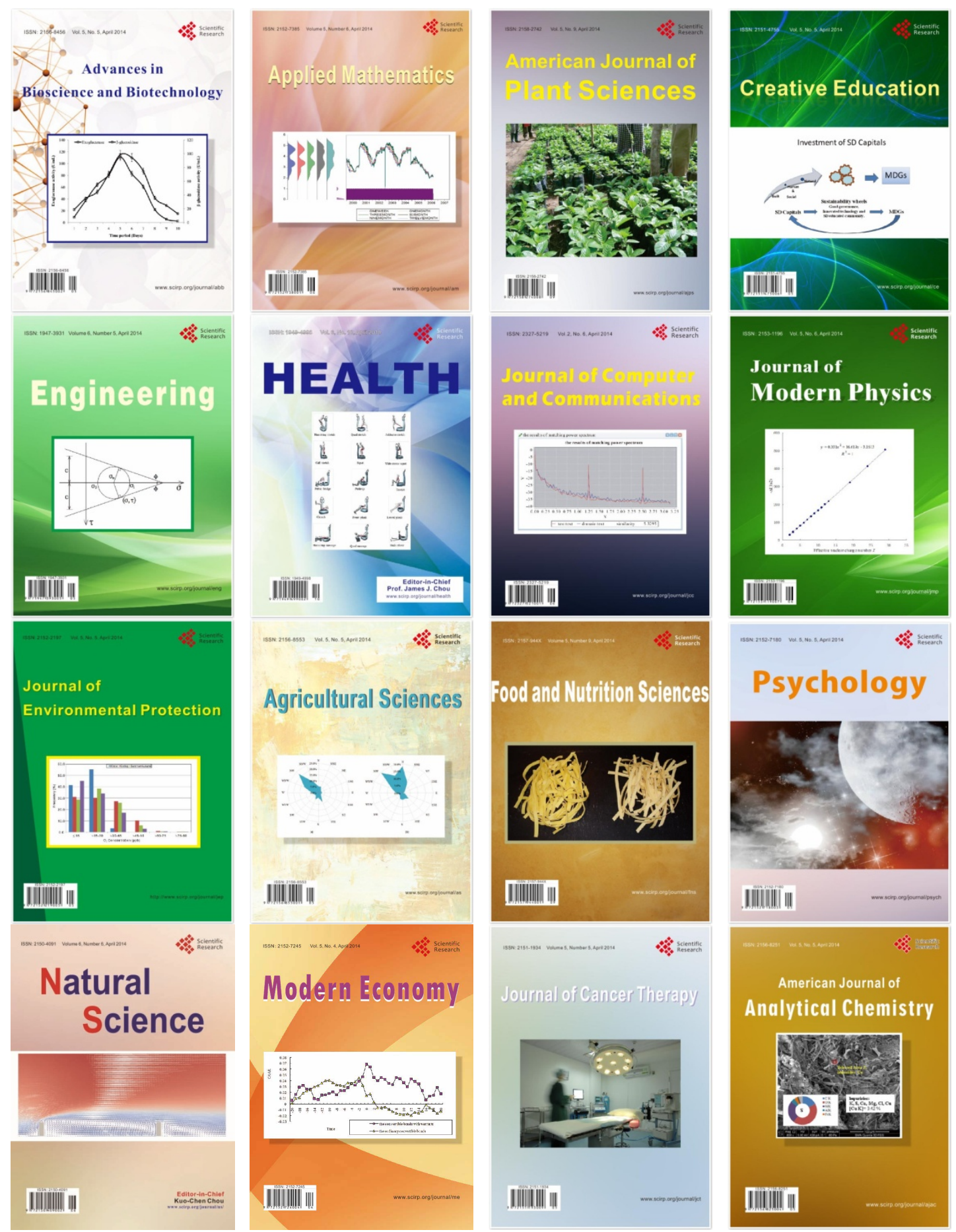